\title{
BMJ Open Shift work, night work and sleep disorders among pastry cookers and shopkeepers in France: a cross- sectional survey
}

\author{
Emilie Pepin, ${ }^{1,2,3}$ Pascal Gillet, ${ }^{4}$ Fabien Sauvet, ${ }^{1,5}$ Danielle Gomez-Merino, ${ }^{1,5}$ \\ Isabelle Thaon, ${ }^{3,6}$ Mounir Chennaoui, ${ }^{1,5}$ Damien Leger ${ }^{1,2}$
}

To cite: Pepin E, Gillet $P$, Sauvet $F$, et al. Shift work, night work and sleep disorders among pastry cookers and shopkeepers in France: a crosssectional survey. BMJ Open 2018;8:e019098. doi:10.1136/ bmjopen-2017-019098

- Prepublication history for this paper is available online. To view these files, please visit the journal online (http://dx.doi org/10.1136/bmjopen-2017019098).

Received 11 August 2017 Revised 23 February 2018 Accepted 7 March 2018

\section{Check for updates}

1 Université Paris Descartes, Sorbonne Paris Cité, EA 7330 VIFASOM (Vigilance Fatigue Sommeil et Santé Publique), Paris, France

${ }^{2}$ APHP, Hôtel-Dieu, Centre du Sommeil et de la Vigilance, Consultation de pathologie professionnelle Sommeil Vigilance et Travail, Paris, France ${ }^{3} \mathrm{CHRU}$ de Nancy, Centre de consultations de pathologies professionnelles, Vandoeuvrelès-Nancy, France

${ }^{4}$ MEDIALANE, Maxeville, France ${ }^{5}$ IRBA (Institut de recherche biomédicale des armées), Unité Fatigue et Vigilance, Bretignysur-Orge, France

${ }^{6}$ EA 7298 INGRES, Université de Lorraine, Vandoeuvre les Nancy, France

Correspondence to

Dr Damien Leger;

damien.leger@htd.aphp.fr

\section{ABSTRACT}

Objective Most research on night and shift work focuses on employee health in large companies, primarily in the healthcare and transportation sectors. However, many night workers work on their own or in small businesses related to services or food. This survey focuses on sleep habits and disorders concerning night work in pastry production and sales.

Methods An epidemiological telephone cross-sectional survey of night shift workers and their sleep habits was proposed to all employers and employees in the French pastry industry via their insurance health prevention company. Sleep logs allow us to estimate the total sleep time (TST) on workdays and enquire on napping episodes and length. In order to estimate the ideal TST, we added a question on the ideal amount of sleep the subjects need to be in good shape in the morning. We also define sleep debt as the difference between the ideal TST and TST on workdays, and considered a sleep debt when the difference was above $60 \mathrm{~min}$ and severe sleep debt above $90 \mathrm{~min}$. Finally we retained subjects as long sleepers for those with a TSTof more than 7 hours and short sleepers when TST was under 5 hours. Insomnia, sleepiness and sleep apnoea have been defined based on the International Classification of Sleep Disorders-Third Edition and the classification of mental disorders (Diagnostic and Statistical Manual of Mental Disorders-Fifth Edition). Bivariate and multivariate logistic regression models were applied to investigate the association with short TST, long TST, sleep debt and napping.

Results We analysed 2622 complete questionnaires from 1313 men and 1309 women aged 22-50 years old. 1397 workers began work before $07: 00$, whereas 1225 began later. The 24-hour TST was $6.7 \pm 1.4$ hours, whereas the ideal TST was $7.0 \pm 1.2$ hours. Severe sleep debt ( $>90 \mathrm{~min}$ ) was reported by $6 \%$ women versus $5 \%$ men, whereas moderate sleep debt (>60 min) was reported by $11.5 \%$ women versus $9.3 \%$ men. Napping is one way to improve 24 -hour TST for $58 \%$ of pastry producers $(75 \pm 13 \mathrm{~min})$ and $23 \%$ of shopkeepers ( $45 \pm 8 \mathrm{~min}$ ). Nevertheless, $26.2 \%$ of the respondents complained of chronic insomnia, especially women aged $45-54$ years old (31\%). Finally, $29.6 \%$ had evocative criteria for obstructive sleep apnoea, although only $9.1 \%$ had a high score on the Berlin Questionnaire.
Strengths and limitations of this study

- The study successfully uses a unique setting of pastry producers and shopkeepers to renew the discussion surrounding the medical impact of night shifts and work schedules on sleep habits and disorders.

- Questionnaires and sleep logs, based on the definitions of the International Classification of Sleep Disorders and the Diagnostic-Third Edition and the Statistical Manual of Mental DisordersFifth Edition were used to assess total sleep time and sleep debt, at night and during each 24-hour period.

- The cross-sectional telephone survey did not provide any explanations on how obesity in pastry professionals may be partially attributed (or not) to sleep debt or sleep disorders.

- The survey, based only on questionnaires, lacks objective assessment by polysomnography or actigraphy and contains no clinical interviews.

Conclusion Our study demonstrates that both pastry producers and shopkeepers can have disturbed sleep schedules and a high prevalence of sleep disorders, although many have used napping as a behavioural countermeasure to fight sleep debt. The results of our survey lead us to conclude that, besides the need to take care of night workers in big industries, more information and occupational prevention must be focused on night workers in individual and small businesses.

\section{INTRODUCTION}

In France, one in five workers can be categorised as a night and/or shift worker. According to French legislation, an employee is considered as a night worker when he or she works for 3 hours between 21:00 and 06:00, at least twice per week. In 2012, $15.2 \%$ of French workers (9\% of all working women and $21.4 \%$ of all working men) worked at night, which represents an increase in comparison with the $13 \%$ working at night in 1991, as well as a higher representation 
among working women (9\% in 2009 vs $5.8 \%$ in 1991). The prevalence of night and shift work is greatest among workers in critical services and public utilities such as healthcare, transportation (42\%), and police and fire protection $(72 \%)$. However, night and shift workers are also found in many small businesses; for example, the proportion has been estimated at $37 \%$ for butchers and bakers. $^{1}$

These night and shift work schedules lead employees to work during periods usually devoted to rest (ie, eating and sleeping), as well as social and familial activities. These irregular hours can include night work, extended work hours, weekend work, fragmented work hours during the day, and irregular variations in the cycle of the number of workdays and work periods. Both night and shift work complicate lifestyle and are associated with the risks of reduced sleep time, increased circadian disturbances and, frequently, psychosocial stress. ${ }^{2}$ Although there is clear individual variability in night and shift work adaptation (ie, delayed, advanced or absent shift phases), ${ }^{3}$ the majority of night and shift workers do not adapt their biological rhythms since their work periods occur during the critical hours of melatonin secretion. ${ }^{4}$ This has three implications for such workers: they are active during a period when brain and body functions slow down; they sleep during a period of minimal sleep propensity; and they are subjected to consecutively shorter and less refreshing daytime sleep.

Depending on their age and sociofamilial cues, many night and shift workers also have difficulties keeping regular social lifestyles. This results in a deleterious sleep debt, which may be associated with increased cardiovascular and metabolic risks, as well as breast cancer pathogenesis. ${ }^{5-7}$

Along with gender or age-related differences in adapting to night and shift work, there are also interindividual differences in the patterns of sleep debt recovery and circadian misalignments that may be related to the particular occupation. Indeed, 'blue collar' night shift workers in an industrial plant do not face the same demands as self-employed pastry producers. In contrast to the numerous surveys that have been conducted in medical settings among night shift nurses or residents, only a few surveys have focused on self-employed manual workers or small business employers. To our knowledge, there is barely any literature about night work in pastry producers, even though this is one of the better known night occupations in our society. More precisely, several surveys have focused on occupational asthma ${ }^{8}$ or health assessment ${ }^{9}$ in pastry producers, but no surveys have addressed sleep.

In the present study, we provide the results from our survey on the sleep habits and disorders in employers and employees of small French pastry businesses. We also report how these workers typically cope with their shifts and night schedules.
MATERIALS AND METHODS

\section{Subjects and sampling design}

To be eligible, each subject had to be affiliated with the national pastry producers database, which includes all self-employed French pastry producers as well as employees of small pastry businesses.

We conducted a cross-sectional study based on telephone surveys using a randomised selection of pastry producers from the national database, using a computerised system (CATI) to select unrestricted mobile and home phone numbers. In the event of no answer or a busy line, the interviewees were called again, up to five times at different times of the week. Pastry producers who did not call back were excluded. The contact methodology was designed such that the sex ratio and age groups constituted a representative sampling of pastry producers.

\section{Patient and public involvement statement}

The questionnaire has been discussed with the pastry maker trade union referees in order to improve participant comprehension of the survey. All pastry makers affiliated with the national pastry producers database, which includes all self-employed French pastry producers as well as employees of small pastry businesses, had received information on the survey via email or phone cells. Results have been presented to the professionals via the diffusion of a PowerPoint presentation to the trade unions and information on sleep hygiene and management via a webphone application iSommeil (in English iSleeping).

\section{Measurements}

Assessing sleep habits and disorders

Previous reports have tested and introduced sleep assessments in several national health surveys on sleep and health. ${ }^{10-12}$ These sleep-specific measurements were based on confirmed sleep logs recommended for sleep assessments in adults ${ }^{13}$ on regular (non-leisure) days. As our survey was designed to be conducted on a single day, we employed several phrases to assess the total sleep time (TST):

\section{Estimating TST and napping on workdays}

1. 'When you have to work the following day, at what time do you usually turn off the light to go to sleep?'

2. 'When you have to work the following day, at what time do you usually wake up?'

3. 'How long does it usually take for you to fall asleep?'

4. 'If you have awakenings during the night, how long do they usually last (in minutes)?'

5. 'Do you regularly nap during workdays? If yes, how often and for how long?'

TST during work periods was defined as the difference between the time at which the participant turns off the light and the time at which he/she wakes up, discounting the time needed to fall asleep and the time to awaken.

\section{Estimating ideal sleep and sleep debt}

In accordance with the literature, we adapted our definition of sleep debt, which may reflect voluntary (due to 
work conditions, transport or leisure) sleep shortening, by adding the following item to the questionnaire. The question aims to quantify the amount of sleep needed by each subject in order to be in good shape during the workday.

1. 'Ideally, if you were able to decide the number of hours of sleep you need to be in good shape, how much time would you wish to devote to sleep? / _ _ / hours /____min'.

We defined sleep debt as the difference between TST 'needed to be in good shape' and TST at night during the work week; this value was referred to as sleep debt when it was $>60 \mathrm{~min}$ and as severe sleep debt when it was $>90 \mathrm{~min}$.

Sleep characteristics and disorders were defined as follows:

- 'Long sleep': according to the International Classification of Sleep Disorders-Third Edition (ICSD-3), 'a long sleeper is an adult who typically sleeps 7 hours or more, but feels well and functions without impairment'. ${ }^{12}$

- 'Short sleep': in adults, sleeping less than 5 hours during workdays is usually considered as the cut-off for 'short sleep' with potential comorbidities. ${ }^{10}{ }^{11}$ We then strictly defined 'short sleepers' as those workers sleeping less than 5 hours.

- Insomnia: according to the definitions of the Diagnostic and Statistical Manual of Mental Disorders-Fifth Edition, ICSD-3 and the American Academy of Sleep Medicine, ${ }^{14} 15$ insomnia is defined as difficulty initiating sleep, difficulty maintaining sleep, early morning awakening or non-restorative sleep, with a frequency of at least three times per week for at least 1 month and with a negative impact on daytime functioning.

Based on these characteristics, we defined the three following categories: no sleep disorders when no difficulties were mentioned; poor sleep when at least one difficulty was mentioned less than three times per week; and insomnia, when it follows the previous definition.

We also posed a specific question on how frequently the subjects experienced sleep disorders during the past 8 days: not at all, a few times, a lot and 'do not know'.

- Sleep apnoea was assessed subjectively via the Berlin Questionnaire. ${ }^{16}$

- Sleepiness was based on the answers to the nine items of the Epworth Sleepiness Scale (ESS). ${ }^{17}$ A score above 10 indicates sleepiness and above 16 indicates severe sleepiness.

\section{Other variables assessed}

- Chronotype was assessed by one single question from the Horne and Ostberg Questionnaire, ${ }^{18}$ which asks whether the subject thinks they are absolutely a morning person, almost a morning person, absolutely an evening person, almost an evening person, and neither a morning nor an evening person or both.

- Transportation time every day, from home to work and back again.
- Sleeping with your mobile phone turned on beside the bed.

\section{Statistical analysis}

Bivariate and multivariable logistic regression models were applied to investigate if any risk factors were independently associated with short TST, long TST and napping. Analyses were performed using the R V.2.12.1 software. The statistics presented (percentages, ORs) correspond to weighted and adjusted results. We used Pearson's $\chi^{2}$ tests in the bivariate analysis; ORs are presented with their $95 \%$ CIs.

\section{RESULTS \\ Sociodemographics}

Out of the 7694 phone calls directed to pastry professionals, $11.95 \%$ refused to participate while $53 \%$ did not complete the full interview. In the end, 2622 complete questionnaires were analysed (comprising 1313 men and 1309 women, with an age range of 22-50 years), yielding a $34 \%$ response rate (figure 1 ). The mean telephone interview duration was $17 \mathrm{~min}$ and $45 \mathrm{~s}$. The sex, age and occupation distributions of the participants did not differ significantly within the distribution of respondents and are presented in table 1.

The average declared weight of the participants was $70 \pm 15 \mathrm{~kg}$. The participants reported an average change in weight of $4 \pm 6 \mathrm{~kg}$ over the last 5 years; $9.1 \%$ gained $10-14 \mathrm{~kg}$ and $6.9 \%$ gained $\geq 15 \mathrm{~kg}$. Furthermore, $27 \%$ of the participants were considered overweight (with a body mass index (BMI) of $\geq 25$ but $<30$ ), whereas $10 \%$ were obese $($ BMI $>30)$. Men were more obese than women across all age groups $(\mathrm{p}<0.001)$.

\section{Work characteristics}

Of the subjects, 262 were either self-employed or employees, and 1520 (78\% men) worked in pastry

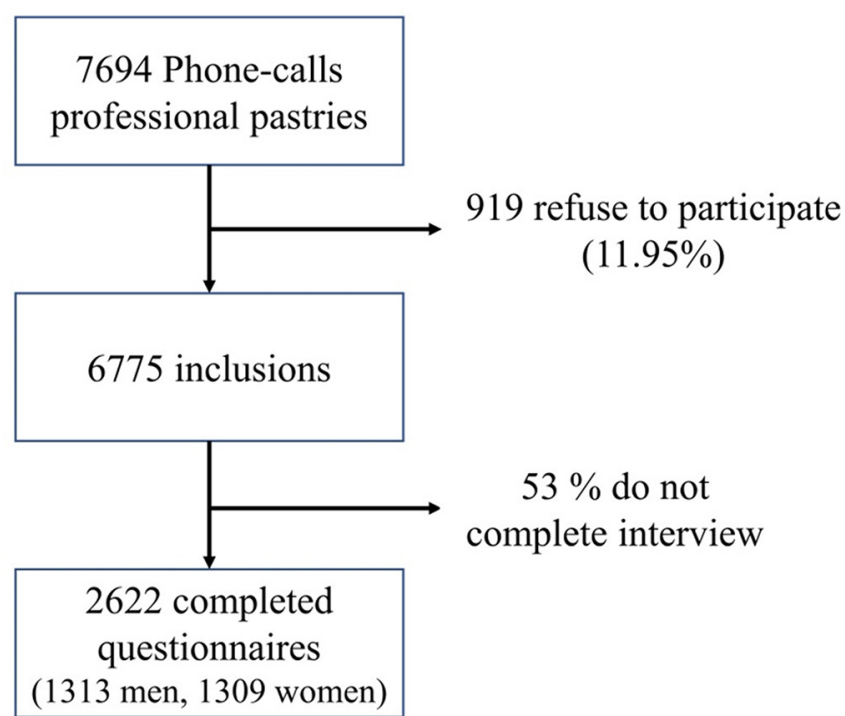

Figure 1 Flow chart of selection of questionnaire respondents. 
Table 1 Characteristics of the population interviewed

\begin{tabular}{|c|c|c|c|}
\hline Characteristics & Men (\%) & Women (\%) & Total (\%) \\
\hline $\mathbf{N}$ & $1313(50)$ & $1309(50)$ & $2622(100)$ \\
\hline \multicolumn{4}{|l|}{ Age (years) } \\
\hline 25-34 & $290(50)$ & $293(50)$ & $583(22)$ \\
\hline $35-44$ & $195(46)$ & $232(54)$ & $426(16)$ \\
\hline $55-64$ & $134(42)$ & $188(58)$ & $322(12)$ \\
\hline \multicolumn{4}{|l|}{ Activity } \\
\hline Producer & $1184(78)$ & $336(22)$ & $1520(58)$ \\
\hline Shopkeeper & $129(12)$ & $973(88)$ & $1102(42)$ \\
\hline \multicolumn{4}{|l|}{ Work start } \\
\hline Before 07:00 & $1011(72)$ & $386(28)$ & 1397 (53) \\
\hline After 07:00 & $302(25)$ & $923(75)$ & $1225(47)$ \\
\hline \multicolumn{4}{|l|}{ Body weight (kg) } \\
\hline$<70$ & $383(29)$ & $923(71)$ & $1306(50)$ \\
\hline $70-79$ & 390 (63) & $232(37)$ & $622(24)$ \\
\hline $80-89$ & $281(75)$ & $95(25)$ & $376(14)$ \\
\hline 90-99 & $164(80)$ & $41(20)$ & 205 (8) \\
\hline$>100$ & 95 (84) & 18 (16) & $113(4)$ \\
\hline
\end{tabular}

production, whereas 1562 subjects worked in sales in pastry shops ( $88 \%$ women). The subjects have held the same occupation for 1-15 years. Of the subjects, $84.9 \%$ worked full time (table 1).

Work schedules, based on the start of a typical shift hour, are presented in figure 2. Most pastry producers at production sites were night workers, of whom $75 \%$ began their shift between 03:00 and 07:00, in comparison with $83 \%$ of pastry shopkeepers who began work between 06:00 and 09:00.

\section{Sleep patterns}

The average TST at night was $6.3 \pm 5.5$ hours in the total group, with a minimum of 5.5 hours for men (35-44 years old) and a maximum of 6.9 for women (25-34 years old). The distributions of the ideal TST, 24-hour TST and TST at night among sex, work (producers or shopkeepers) and employee versus employer status, work start time, body weight and napping are detailed in table 2 .

The ideal TST was significantly greater in the following groups: women, pastry shopkeepers, employees, subjects who started their job after 07:00, subjects weighing less than $70 \mathrm{~kg}$ and subjects who do not regularly nap. This ideal TST was on average 7.0 \pm 1.2 hours in duration; $63.6 \%$ of the subjects declared needing more than 7 hours, $33.8 \%$ declared needing 5-7hours and 2.6\% declared needing less than 6 hours of sleep.
Night TST was smaller than the ideal TST for each category and was significantly lower $(p<0.01)$ in the following groups: male pastry producers, employers, those starting work before 07:00, those weighing more than $100 \mathrm{~kg}$ and those who took naps. However, taking into account nap length, 24-hour TST increased significantly in almost all categories and did not differ from the ideal TST in producers and subjects who napped.

The amount of sleep debt in 24 hours was significantly higher in the following groups: women, shopkeepers, employers, subjects weighing less than $70 \mathrm{~kg}$ and subjects who did not take naps.

Forty-three per cent of the subjects reported napping on a regular basis, concerning $23 \%$ of shopkeepers versus $58 \%$ workers at production sites $(\mathrm{p}<0.01)$. Napping also increased with age in men and women, in shopkeepers and in production staff. Nap duration was significantly different between production staff $(75 \pm 13 \mathrm{~min})$ and shopkeepers $(45 \pm 8 \mathrm{~min}) \quad(\mathrm{p}<0.01)$. In both groups, nap duration decreased regularly with increasing age groups.

Regarding chronotype, $54.1 \%$ considered themselves as 'absolutely or almost a morning person', $20.7 \%$ as 'absolutely or almost an evening person', 19\% as 'both', $4 \%$ as 'neither' and the final $2 \%$ were uncertain. 


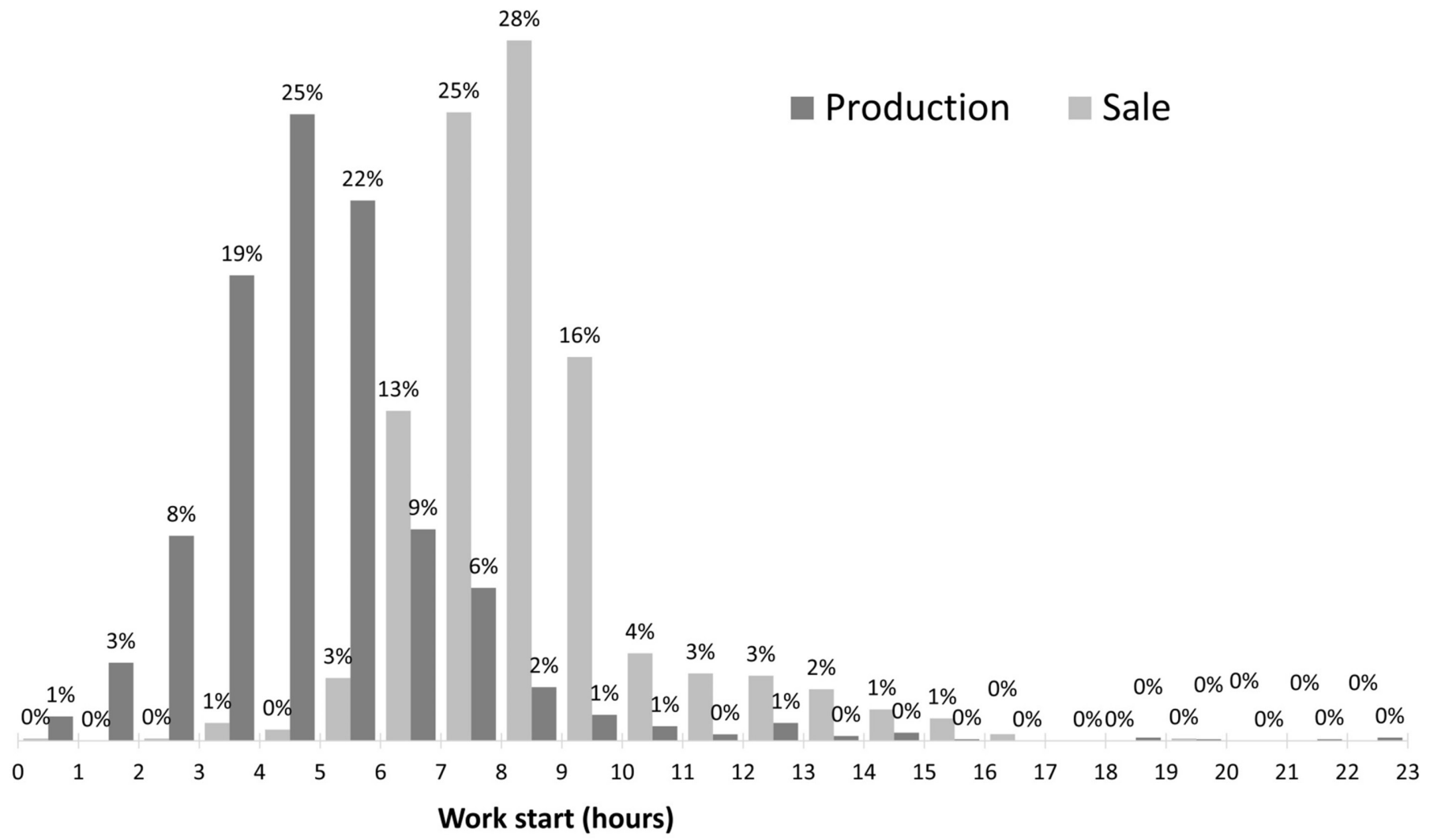

Figure 2 Work start schedule according to the job.

More than one out of two subjects (57\%) reported sleeping with their mobile phones turned on next to their bed.

\section{Sleep disorders}

Of the respondents, $26.2 \%$ complained of chronic insomnia according to the ICSD-3 definition. The highest rate observed was for women in comparison with men, regardless of age group $(24.1 \%$ vs $19.5 \%$; $<<0.05)$, with the highest rate $(31 \%)$ occurring for women aged 45-54years old (tables 3, 4 and 5).

Sleep debt did not significantly differ between women and men: $6 \%$ of women vs $5 \%$ of men reported severe sleep debt $(>90 \mathrm{~min})$, while $11.5 \%$ of women vs $9.3 \%$ of men reported moderate sleep debt $(>60 \mathrm{~min})$. In addition, the rate of severe sleep debt did not differ among age groups. Subjects exhibiting obesity had a $14 \%$ risk of severe sleep debt, in comparison with $19 \%$ of subjects with a normal weight $(\mathrm{p}<0.02)$.

Out of the total group, $12.4 \%$ complained of moderate excessive sleepiness (ESS $>10$ ) while $2.9 \%$ reported severe excessive sleepiness (ESS $>16$ ), with no differences between the sexes. Men aged 45-54 years reported the highest rate $(23 \%)$, in comparison with $13 \%$ in the age group 35-44years old $(\mathrm{p}<0.01)$. Of the subjects, $21.1 \%$ reported sleeping frequently while driving. Subjects exhibiting obesity had a non-significantly higher risk of excessive sleepiness in comparison with subjects with a normal weight $(\mathrm{p}<0.001)$.
On the Berlin Questionnaire, 29.6\% of the subjects had a score indicating a risk of obstructive sleep apnoea (OSA), which was significantly higher in men than in women $(\mathrm{p}<0.01)$; out of this group, $40.8 \%$ had a low score, $50.1 \%$ had a moderate score and $9.1 \%$ had a high score. A high risk score of sleep apnoea also increased significantly according to age group, from $5 \%$ in the age group 15-24years old vs $19 \%$ in the age group $>55$ years old $(p<0.001)$. Subjects exhibiting obesity had a $50 \%$ higher risk of OSA, in comparison with $3 \%$ for subjects with a normal weight $(\mathrm{p}<0.001)$.

\section{Sleep habit disorders and work characteristics}

Short sleepers (receiving less than 5 hours of sleep per night) represented $78.8 \%$ of the subjects working at production sites (vs 21.2\% in pastry shops) $(\mathrm{p}<0.001)$. This category concerns $28 \%$ of subjects who usually begin their shift before $07: 00$, as compared with $7.4 \%$ of subjects with later schedules $(\mathrm{p}<0.001)$ (tables 2, 3, 4 and 5).

Insomnia was reported at a significantly higher level by shopkeepers $(32.8 \%)$ than by pastry producers $(22.5 \%) \quad(\mathrm{p}<0.05) \quad($ table 3$)$, as well as by participants who begin work after 07:00. Severe sleep debt was significantly higher in employees and shopkeepers than in employers and producers, and increased for workers with earlier schedules. Severe sleepiness was significantly higher in producers, employers and subjects who begin work after 07:00, as compared with the other categories. OSA cannot explain these differences, since 


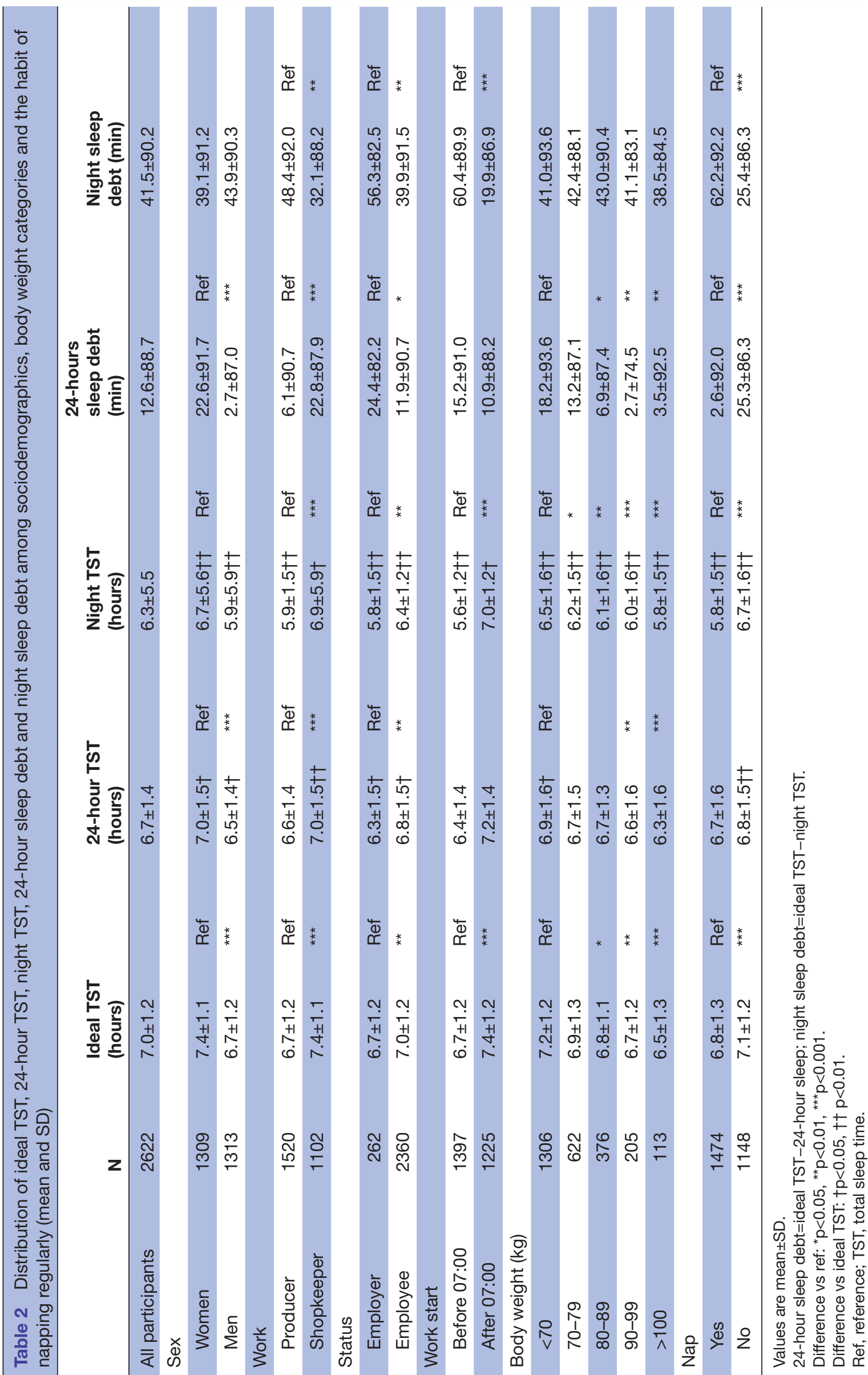




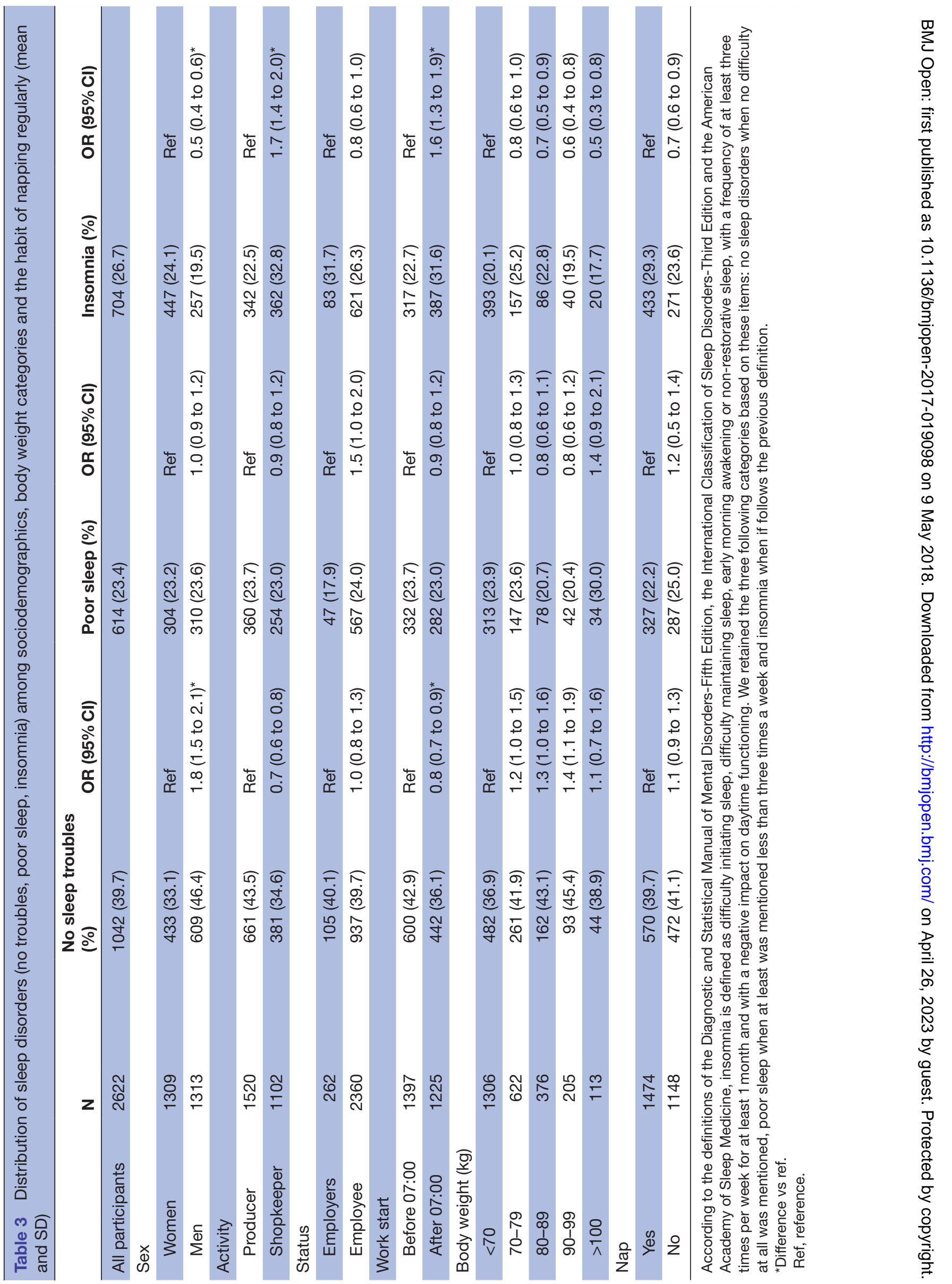




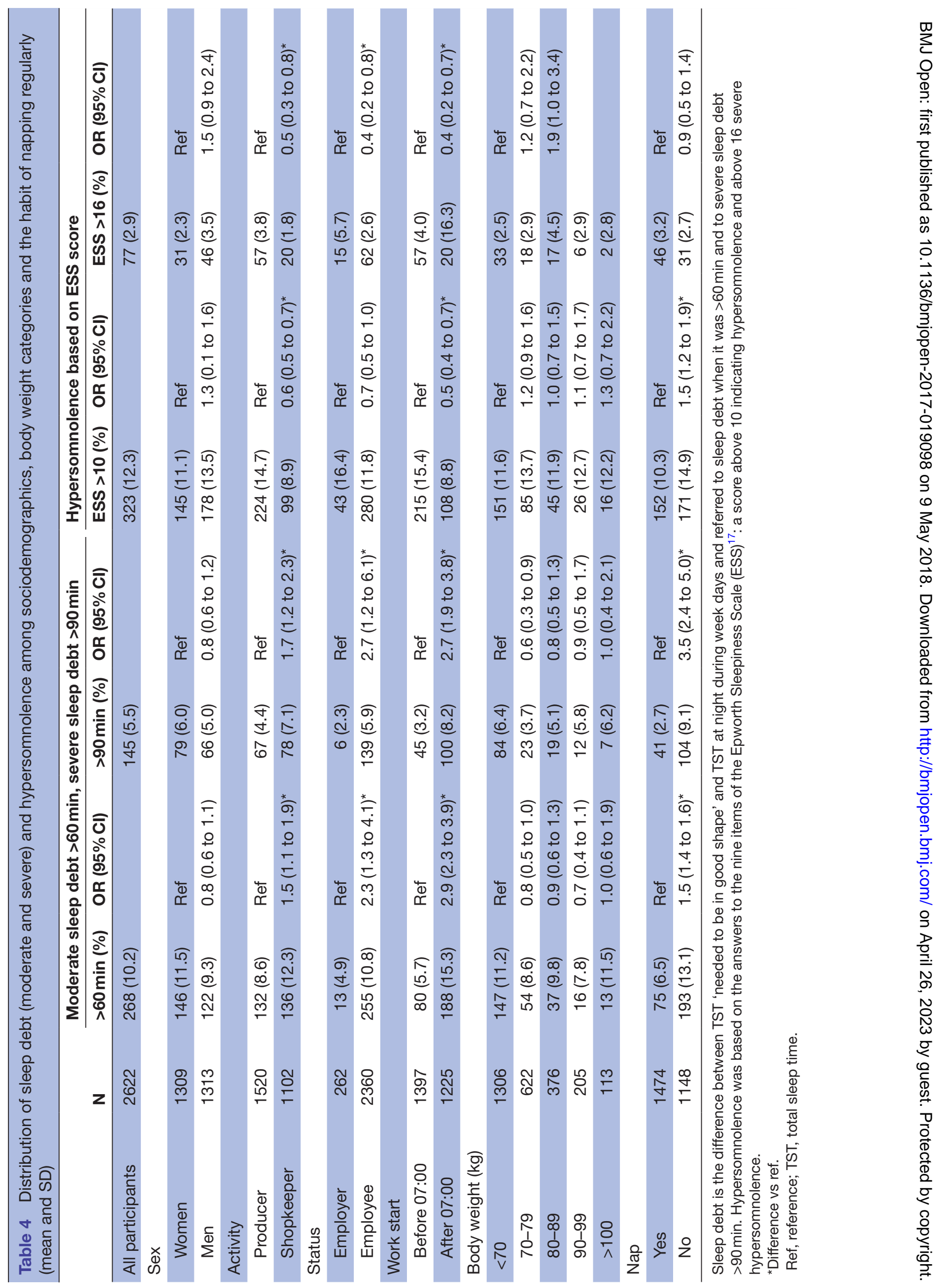




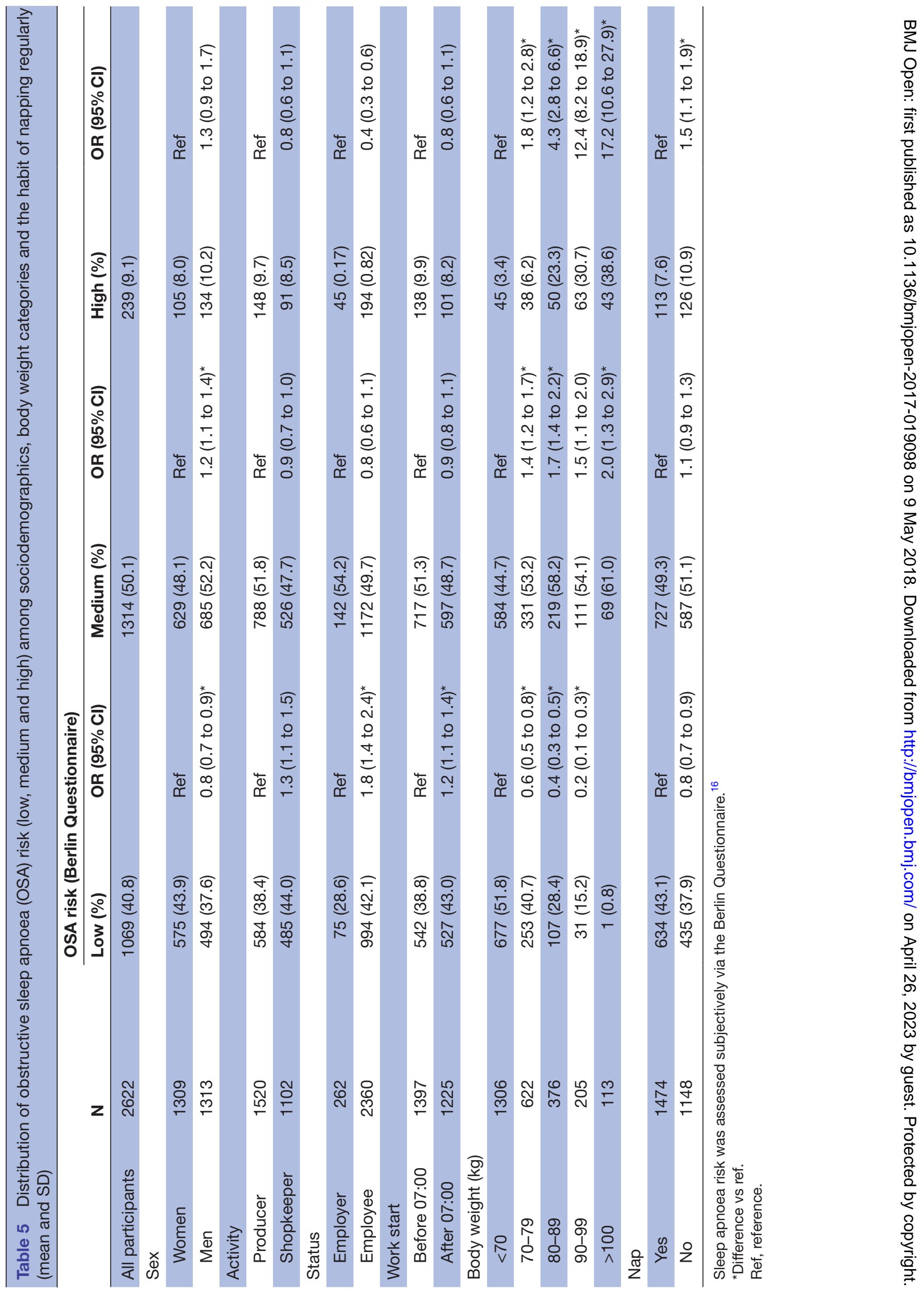


the rate of OSA did not differ among the various work characteristics.

\section{DISCUSSION}

This study examines the unique setting of pastry producers and shopkeepers, providing a valuable opportunity to revisit the medical impact of work schedules on sleep habits and disorders. It is well reported that night work or irregular shifts have consequences on sleep, sleepiness and health, notably including metabolism, cardiovascular diseases $^{1920}$ and even breast cancer. ${ }^{21}$ These disorders have been attributed to the biological desynchronisation that affects melatonin and other hormonal cycles around the 24-hour cycle, ${ }^{22}$ as well as the amount of sleep debt that is associated with numerous metabolic and cardiovascular disorders. Night and shift work sleep disorders have been described and classified in the ICSD-3. ${ }^{14}$

Prior to this study, most of the literature devoted to shift work disorders was based on studies conducted on employees of large companies, especially in industry, transportation, energy, police and health. ${ }^{23}{ }^{24}$ The latter occupations concern civil servants, who can be compensated for their night work with less hours of work per week than regular workers, early retirement or even pay that is on average $20 \%$ more than regular workers. ${ }^{25}$

To our knowledge, few studies have been devoted to small business workers and shopkeepers. For this reason, we chose to focus on pastry producers and shopkeepers, who are well known for their night-shifted business. Indeed, we observed in our survey that a large number of professionals in the pastry industry had disturbed sleep schedules and sleep disorders. However, the subjects differ from one group to the other, depending on their autonomy and ability to cope with their shifts and schedules.

In comparison with the total group, pastry producers at production sites exhibited the most reduced TST at night $(5.9 \pm 1.5$ hours vs $6.9 \pm 5.9$ hours $)$. These workers were mostly men who began their work at the earliest hours (in the middle of the night). Therefore, it should not be surprising that they declared the most important sleep debt in our survey. However, we also observed that this group reported the longest, most frequent periods of napping among our study groups (62.2 $\mathrm{min}$ vs $25.4 \mathrm{~min}$ ).

With the help of napping, subjects were able to situate their 24-hour TST closer to the 7 hours recommended for regular workers. This group of independent professionals has therefore applied the recommendations that are given for night and shift workers. ${ }^{26}$ Indeed, napping is recognised as an excellent means to increase TST in night workers. ${ }^{27}$ Specifically, it may help them to improve daytime alertness, ${ }^{28}{ }^{29}$ to reduce the risk of accidents while driving, and even to reduce the metabolic and cardiovascular risks associated with chronic short sleep. ${ }^{30} 31$

In our subgroup of pastry producers, the proportion of respondents who experienced sleepiness while driving was clearly high $(21.1 \%)$. Furthermore, the percentage of obesity and overweight workers was greater than in the general population. ${ }^{32}{ }^{33}$ It must be noted that this is a cross-sectional survey and we cannot conclude on the relationship between TST, napping and being overweight. Certainly, pastry producers can be susceptible to other possible causes of obesity, but these were not investigated in this survey. Aside from reduced TST and weight issues, we also observed a high risk of OSA in our participants $(10.2 \%$ in men vs $8 \%$ in women, $\mathrm{p}<0.05)$. It is important to assess this risk, since surveys of night and shift work have mainly drawn conclusions on the effect of sleep debt on sleepiness, without assessing OSA. Indeed, OSA is a major cause of sleepiness, and it is important, even within the workplace, to not overlook the possibility of sleep disorders such as OSA that are associated with other causes of sleepiness.

It is important to note that the definition of 'sleep debt' that we have applied in this study is based on the difference between TST on work days and an 'ideal sleep' (according to the interviewed subjects). However, it was previously demonstrated that sleep duration beliefs may augment and bias the ideal sleep duration reported by subjects, in particular in individuals with symptoms of insomnia. ${ }^{34}$ Thus, there is the possibility that this may have artificially increased the amount of 'sleep debt' reported in our survey responses.

Aside from the previous findings, pastry shopkeepers had the highest rate of insomnia. These subjects were mainly women, and a high percentage also had early work hours, even if this is not similar to pastry producers who must rise in the middle of the night. ${ }^{35}$ An early work schedule, including opening a shop at 06:00 or 07:00, ideally requires going to bed not too late, which can be difficult when the worker must close the shop at 19:00 or 20:00. This group of shopkeepers is also affected by a short sleep period $(21.2 \%$ of respondents had a TST less than 5 hours) and by sleep debt $(7.1 \%$ of respondents). In addition to early morning work, a number of working conditions can influence insomnia, including stress induced by the management of personal affairs and occasionally difficult relationships with clients. However, our survey was not concerned with these possible causes. Moreover, it may be possible that when considering ideal sleep, subjects should not think of it in terms of occurring within a 24-hour period, but rather as ideal sleep in one single episode of night sleep. This point may have also biased the concept of sleep debt.

Finally, we acknowledge that our study has several limitations. First, this is a questionnaire study, and sleep habits and disorders assessed by questionnaires and phone calls can only reflect the subjective feelings of the people interviewed. By comparison, objective measurements of sleep such as polysomnography or actigraphy are considered the gold standards for assessing sleep and sleep disorders. ${ }^{14}$ In addition to these complementary assessments, some clinical diagnoses, such as insomnia, must be confirmed by clinical interviews. Nevertheless, the participants in our study completed questionnaires that were based on consensual international 
classifications $^{1415}$ and that have previously been used in many studies in the general population. ${ }^{10-12}$ Second, the response rate to our survey was quite low; thus, it is not possible to consider the sample as a representative group of pastry producers and shopkeepers. However, the sociodemographic characteristics of the subjects who accepted to be interviewed, which comprised a reasonable group of workers, did not differ from pastry professionals in the broader population.

In conclusion, our study demonstrates that both pastry producers and shopkeepers can have disturbed sleep schedules and a high prevalence of sleep disorders, although many have used napping as a behavioural countermeasure to fight sleep debt. The results of our survey lead us to conclude that, besides the need to take care of night workers in big industries, more information and occupational prevention must be focused on night workers in individual and small businesses.

Acknowledgements We thank the National 'Branche Professionnelle des Patissiers', which advised and supported the survey. We also thank all the professionals who responded and participated in the survey.

Contributors Conception or design of the work: DL, PG, FS. Acquisition, analysis, interpretation of data and manuscript editing: EP, PG, DG-M, IT, MC, DL. All authors have reviewed and approved the final manuscript.

Funding This survey was financed and supported by the healthcare plan of the occupational branch of the craft pasty making, covered by an unrestricted grant from AG2R-La Mondiale, a French insurance company that covers some of the health expenses of pastry producers and shopkeepers.

Competing interests $\mathrm{DL}$ is or has been consulted as the main investigator in studies sponsored by Actelion, Agence Spatiale Européenne, AG2R, Bioprojet, CNES, DGA, iSommeil, Jazz, Vanda, Merck, NASA, Philips, ResMed, Sanofi, Rhythm, Vinci Fondation and VitalAire in the last 5 years. He declares no $\mathrm{COI}$ regarding this manuscript. PG has received funding from AG2R to interview subjects with Maxilane. None of the other authors declared any conflict of interest.

\section{Patient consent Not required.}

Ethics approval Participation was anonymous and voluntary. As an epidemiological survey, the study protocol was approved by the French Commission on Information Technologies and Liberties (CNIL, Commission nationale informatique et libertés) on condition of the anonymous nature of the study and the guarantee that the selected phone numbers would be erased from the database after the study, as well as by the delegate council of the National Pastry Makers Union with guarantee that the results would not be used to identify any of the subjects.

Provenance and peer review Not commissioned; externally peer reviewed.

Data sharing statement No additional data are available.

Open Access This is an Open Access article distributed in accordance with the Creative Commons Attribution Non Commercial (CC BY-NC 4.0) license, which permits others to distribute, remix, adapt, build upon this work non-commercially, and license their derivative works on different terms, provided the original work is properly cited and the use is non-commercial. See: http://creativecommons.org/ licenses/by-nc/4.0/

(C) Article author(s) (or their employer(s) unless otherwise stated in the text of the article) 2018. All rights reserved. No commercial use is permitted unless otherwise expressly granted.

\section{REFERENCES}

1. Algava E. Le travail de nuit en 2012. Essentiellement dans le tertiaire. DARES Analyses, août 2014, №62; 2014. http://dares.travail-emploi. gouv.fr/IMG/pdf/2014-062.pdf (cited 2017 Jun 17)

2. Metlaine A, Sauvet F, Gomez-Merino D, et al. Association between insomnia symptoms, job strain and burnout syndrome: a cross-sectional survey of 1300 financial workers. BMJ Open 2017:7:e012816.

3. Juda M, Vetter C, Roenneberg T. Chronotype modulates sleep duration, sleep quality, and social jet lag in shift-workers. J Biol Rhythms 2013;28:141-51.

4. Gibbs M, Hampton S, Morgan L, et al. Adaptation of the circadian rhythm of 6-sulphatoxymelatonin to a shift schedule of seven nights followed by seven days in offshore oil installation workers. Neurosci Lett 2002;325:91-4.

5. Knutsson A. Health disorders of shift workers. Occup Med 2003;53:103-8.

6. Pan A, Schernhammer ES, Sun Q, et al. Rotating night shift work and risk of type 2 diabetes: two prospective cohort studies in women. PLoS Med 2011;8:e1001141.

7. Wang X-S, Armstrong MEG, Cairns BJ, et al. Shift work and chronic disease: the epidemiological evidence. Occup Med 2011;61:78-89.

8. Rémen T, Acouetey D-S, Paris C, et al. Early incidence of occupational asthma is not accelerated by atopy in the bakery/ pastry and hairdressing sectors. Int J Tuberc Lung Dis Off $J$ Int Union Tuberc Lung Dis 2013;17:973-81.

9. Lesage F-X, Deschamps F. Évaluation de l'état de santé d'une population d'artisans et de commerçants. Arch Mal Prof Environ 2005;66:456-64.

10. Léger D, Roscoat E, Bayon V, et al. Short sleep in young adults: Insomnia or sleep debt? Prevalence and clinical description of short sleep in a representative sample of 1004 young adults from France. Sleep Med 2011;12:454-62.

11. Léger D, Beck F, Richard JB. Sleep Loss in the Homeless-An Additional Factor of Precariousness: Survey in a Group of Homeless People. JAMA Intern Med 2017;177:278-9.

12. Léger D, Beck F, Richard JB, et al. The risks of sleeping "too much". Survey of a National Representative Sample of 24671 adults (INPES health barometer). PLoS One 2014;9:e106950.

13. Natale V, Léger D, Bayon V, et al. The consensus sleep diary: quantitative criteria for primary insomnia diagnosis. Psychosom Med 2015;77:413-8

14. American Academy of Sleep Medicine. International Classification of Sleep Disorders. Diagnostic and Coding Manual. Darien,III. 3rd edn: American Academy of Sleep Medicine, 2014.

15. American Psychiatric Association. Diagnostic and Statistical Manual of Mental Disorders. 5th Edition. Arlington, VA: American Psychiatric Association, 2013

16. Netzer NC, Stoohs RA, Netzer CM, et al. Using the Berlin Questionnaire to identify patients at risk for the sleep apnea syndrome. Ann Intern Med 1999;131:485-91.

17. Johns MW. A new method for measuring daytime sleepiness: the Epworth sleepiness scale. Sleep 1991;14:540-5.

18. Horne JA, Ostberg O. A self-assessment questionnaire to determine morningness-eveningness in human circadian rhythms. Int $J$ Chronobiol 1976;4:97-110.

19. Sridhar GR, Sanjana NS. Sleep, circadian dysrhythmia, obesity and diabetes. World J Diabetes 2016:7:515-22.

20. Faraut B, Touchette E, Gamble H, et al. Short sleep duration and increased risk of hypertension: a primary care medicine investigation. J Hypertens 2012;30:1354-63.

21. Wegrzyn LR, Tamimi RM, Rosner BA, et al. Rotating Night-Shift Work and the Risk of Breast Cancer in the Nurses' Health Studies. Am J Epidemiol 2017;186:532-40.

22. Haus E, Smolensky M. Biological clocks and shift work: circadian dysregulation and potential long-term effects. Cancer Causes Control 2006;17:489-500.

23. Waage S, Moen BE, Pallesen S, et al. Shift work disorder among oil rig workers in the North Sea. Sleep 2009;32:558-65.

24. Asaoka S, Aritake S, Komada Y, et al. Factors associated with shift work disorder in nurses working with rapid-rotation schedules in Japan: the nurses' sleep health project. Chronobiol Int 2013;30:628-36.

25. Knauth $\mathrm{P}$, Jung $\mathrm{D}$, Bopp W, et al. Compensation for unfavorable characteristics of irregular individual shift rotas. Chronobiol Int 2006;23:1277-84.

26. ANSES. Evaluation des risques sanitaires pour les professionnels exposés à des horaires de travail atypiques notamment de nuit. Maison Alfort: Rapport d'expertise collective, 2016.

27. Arora V, Dunphy C, Chang VY, et al. The effects of on-duty napping on intern sleep time and fatigue. Ann Intern Med 2006;144:792-8.

28. Centofanti SA, Hilditch CJ, Dorrian J, et al. The impact of short nighttime naps on performance, sleepiness and mood during a simulated night shift. Chronobiol Int 2016;33:706-15.

29. Ruggiero JS, Redeker NS. Effects of napping on sleepiness and sleep-related performance deficits in night-shift workers: a systematic review. Biol Res Nurs 2014;16:134-42. 
30. Faraut B, Boudjeltia KZ, Dyzma M, et al. Benefits of napping and an extended duration of recovery sleep on alertness and immune cells after acute sleep restriction. Brain Behav Immun 2011;25:16-24.

31. Faraut B, Andrillon T, Vecchierini MF, et al. Napping: A public health issue. From epidemiological to laboratory studies. Sleep Med Rev 2017;35:85-100.

32. Charles M-A. Obésité : que nous dit l'épidémiologie ? Cahiers de Nutrition et de Diététique 2011;46:167-72.
33. Charles MA, Basdevant A, Eschwege E. Prévalence de l'obésité de l'adulte en France La situation en 2000. 2008 http://www.emconsulte.com/en/article/75473 (cited 2017 Jul 12).

34. Carney CE, Edinger JD, Morin CM, et al. Examining maladaptive beliefs about sleep across insomnia patient groups. $J$ Psychosom Res 2010;68:57-65.

35. Korompeli A, Chara T, Chrysoula L, et al. Sleep disturbance in nursing personnel working shifts. Nurs Forum 2013;48:45-53. 